and clinical examinations acquired over adult clinical exposure are not entirely transferrable to children hence it is anticipated that they do so with apprehension.

Methods A questionnaire was developed and made available online. The list of clinical skills and examinations used in this questionnaire were derived from the set of learning objectives provided to students prior to their placement. In addition to basic demographics, frequency of clinical skills, history-taking and the confidence at which they were performed were collected. Data was collected from 90 medical students.

Results Only a proportion of students could identify a cardiopulmonary arrest on their attachment. This could be explained by lack of confidence in interacting with children. It appears that District General Hospitals offer more learning opportunities in paediatrics than tertiary institutions.

Conclusions Learning objectives are not being met by all students on attachment at St George's Medical School London. This could be due to the lack of learning opportunities such as teaching, feedback given and varying clinical environments.

\section{SIMPLE METHODS TO HELP IMPROVE PAEDIATRIC MEDICAL STUDENT EDUCATION: AN EXAMPLE}

doi:10.1136/archdischild-2012-302724.1017

E Pascall, Bristol University Medics Paediatric Society. University of Bristol, Bristol, UK

There have been huge efforts to improve medical education including paediatrics. However, most is aimed at graduate level rather than medical school. The latter needs to be focused on more as unlike other specialities, paediatrics cannot use the student-led learning of clerking patients on wards as much. This is due to the strict yet important regulations upheld on wards to protect those children and their parents.

The report sets out an example of how students in the Bristol University Medics Paediatric Society encouraged additional learning of paediatrics in a simple yet effective way. Such approaches are valuable in this time of limited resources and target constraints.

The society held a mock OSCE for 60 fourth year students about to take their paediatric OSCE exam. Thirty-five schoolgirls aged 8 to 11 years acted as the patients. All had parental consent with parents the evening. Students mainly practiced the clerking station of their OSCE exam consisting of a ten-minute station to take a history from a parent and examine a child. Fifth years and F1s acted as examiners marking crib sheets so students could learn from the session and improve their examinations. Each student was also given a handout with the exam format, sample examinations and some simple exam tips.

The feedback was mainly positive and showed ways to further improve things in the future. This model can be applied to other specialities and is a simple yet effective student-led approach to encouraging and furthering medical student learning.

\section{THE USE OF VIDEO PODCAST IN PAEDIATRIC UNDERGRADUATE TEACHING. AN ONLINE SURVEY}

doi:10.1136/archdischild-2012-302724.1018

D Son. Paediatrics, Queen Mary's Hospital for Children, St Helier Hospital, Carshalton, UK

Background and Aims E-learning resources such as podcasts have become a commonly used tool in undergraduate medical education. We conducted a survey of medical students during their Paediatric attachments using an online questionnaire. We wanted to know what they think about having an e-learning resource in addition to more traditional learning methods.
Methods A total of 90 medical students were given the opportunity to revise teaching material in the format of a video podcast. The content of the podcast was identical to a previously attended live lecture. All students were contacted via email with a link to an online survey tool. The questions covered areas such as usefulness, user friendliness, advantages and disadvantages over more traditional learning and teaching methods.

Results The majority of the students found the video podcast helpful and easy to access. Some also commented that the video aspect compared to audio only podcasts enhanced the learning effect. Only a small number would prefer podcasts to completely replace traditional lectures.

Conclusions There clearly was a high acceptance of the video podcast, not necessarily as a replacement of traditional lectures, but as a useful tool for revison. It not only has a role in Paediatric but the whole spectrum of medical undergraduate education.

\section{MINISTRY OF ETHICS - A VALUABLE ONLINE RESOURCE FOR PAEDIATRIC ETHICS AND LAW}

doi:10.1136/archdischild-2012-302724.1019

${ }^{1} \mathrm{M}$ Baxter, ${ }^{1} \mathrm{~A}$ Brown-Kerr, ${ }^{2} \mathrm{JCK}$ Wong, ${ }^{3} \mathrm{PY}$ Xiu, ${ }^{4} \mathrm{R}$ Ross-Russell. ${ }^{1}$ University of Cambridge School of Clinical Medicine, Cambridge; ${ }^{2}$ Calderdale and Huddersfield NHS Trust, Huddersfield; ${ }^{3}$ North Middlesex Hospital, North Central London Deanery, London; ${ }^{4}$ University of Cambridge \& Addenbrooke's Hospital, Cambridge, UK

Background and Aims Doctors involved in child health face unique and ever changing legal and ethical challenges. The Institute of Medical Ethics introduced a Consensus Statement (2010) which provided key learning objectives for doctors in medical ethics and law (MEL) including child health. However, a comprehensive online resource covering these topics remains deficient. Our aim was to address this deficiency with a freely accessible learning resource for the UK and Europe.

Methods MinistryofEthics.co.uk was designed to cover a widerange of UK MEL topics. Using feedback from collaborating senior doctors in child health, we identified four main paediatric topics: child protection, mental health and disability, end of life, and general paediatrics. Great emphasis was placed in using a variety of online mediums to target differences in individual learning styles. Use of freely available web-authoring software and new video production technologies allowed for the creation of voice-over animations, all presented on a website specifically designed for enhanced MEL learning.

Results We produced a comprehensive set of paediatric topic and case study notes, 3D-video animation of real-life ethical scenarios, a purpose built MCQ database with graphical user statistics, and online sharing of files and comments between learners and educators. We continue to experience a rapid expansion of our user base, corroborated by an overwhelmingly positive user response.

Conclusion A free-to-use interactive online resource is now available enabling students and clinicians to learn about paediatric MEL using a variety of media and self-assessments. Our low-budget approach is easily updatable to reflect changes in legislation.

\section{STUDENTS SELF-ASSESSMENT IN PEDIATRICS IN AL-OADISIAH UNIVERSITY SCHOOL OF MEDICINE (IRAO)}

doi:10.1136/archdischild-2012-302724.1020

${ }^{1} \mathrm{MM}$ Al-Shamoosi, 'NN Al-Hajjiah, ${ }^{2} \mathrm{~S}$ Al-Zamili. 'Pediatrics, Al-Oadisiah University School of Medicine; 2 Planning and Health Education, Health Office, Diwaniah, Iraq

Objective Student self-evaluation is an important component of clinical education and also of a comprehensive clinical evaluation system. Our aim was to determine whether student self-evaluation is a reliable method of student evaluation system in our college. 